\title{
Boundary Layer Eddies at the Goodnoe Hills Site
}

\author{
C. I. Aspliden \\ L. L. Wendell \\ K. S. Clem \\ G. L. Gower
}

May 1991

Prepared for the U.S. Department of Energy under Contract DE-AC06-76RLO 1830

Pacific Northwest Laboratory Operated for the U.S. Department of Energy by Battelle Memorial Institute 


\title{
DISCLAIMER
}

This report was prepared as an account of work sponsored by an agency of the United States Government. Neither the United States Government nor any agency thereof, nor Battelle Memorial Institute, nor any of their employees, makes any warranty, expressed or implied, or assumes any legal liability or responsibility for the accuracy, completeness, or usefulness of any information, apparatus, product, or process disclosed, or represents that its use would not infringe privately owned rights. Reference herein to any specific commercial product, process, or service by trade name, trademark, manufacturer, or otherwise does not necessarily constitute or imply its endorsement, recommendation, or favoring by the United States Government or any agency thereof, or Battelle Memorial institute. The views and opinions of authors expressed herein do not necessarily state or reflect those of the United States Government or any agency thereof.

\author{
PACIFIC NORTHWEST LABORATORY \\ operated by \\ BATTELLE MEMORIAL INSTITUTE \\ for the \\ UNITED STATES DEPARTMENT OF ENERGY \\ under Contract DE-ACO6-76RLO 1830
}

Printed in the United States of America

Availabie to DOE and DOE contractors from the

Office of Scientific and Technical Information, P.O. Box 62, Oak Ridge, TN 37831;

prices available from (615) 576-8401. FTS 626-8401.

Availahle to the public from the National Technical Information Service,

U.S. Department of Commerce, 5285 Port Royal Rd., Springfield, VA 22161. 
PNL -6940

UC -261

BOUNDARY LAYER EDDIES AT

THE GOOONOE HILLS SITE
C. 1. Aspliden
L. L. Wende 11
K. S. Clem
G. L. Gower

May 1991

Prepared for
the U.S. Department of Energy
under Contract DE-Aco6-76RLO 1830

Pacific Northwest Laboratory

Richland, Washington 99352 


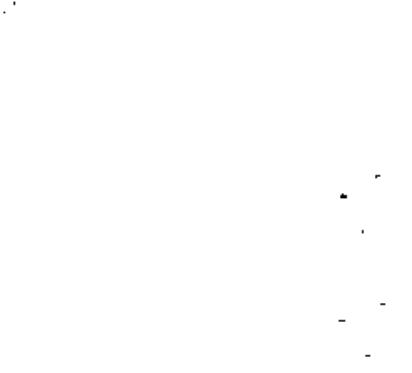


Data from nine instrumented meteorological towers at the MoD-2 wind turbine site at Goodnoe Hills in Washington State were analyzed to evaluate highfrequency perturbations, which were observed in the lower boundary-layer flow. Horizontal winds and temperature measurements for a period of 8 nin, undiswurbed by turbine operation, were avallable for this study. The data are in $1-5$ values from June $27,1985$.

Throughout the study, departures from the mean for the period and for each sensor were used on area maps and on line-time (a) $_{\text {and tower-time }}^{(b)}$ cross sections. Conventional streamline and isotach analyses were employed; they show highly organized flow fields with embedded perturbations traversing the site. Most of the flow fields have a well-developed vortical structure that reaches from the surface through the top level of the highest tower (350 ft or $107 \mathrm{n})$. These structures consist of a systen of clockwise and counter* clockwise circulations. The wave length is about 500 to 600 m. Their wave speed is slightly greater than the mean wind speed and their movenent is in the general direction of the mean flow.

The perturbation axes slope with height in the direction of movement as a result of drag against the ground. They are very pronounced and distinct in the relative wind field and are on the order of 10 nt wide. Similarly, asymptotes and shear lines in general are very well defined.

The site was divided into triangles with a tower in each apex, so that divergence calculations could be carried out. The inflow and outflow values are on the order of $\pm 10^{-2} 5^{-1}$, which is in agreenent wh the lengths of the sides of the triangles. Areas governed by clockwise clrculations show divergence, and counterclockwise circulations are convergent. This indicates a very intricate but well organized three-dimensional mixing system.

The results of the study show two main reasons why wind condtions and turbine power output in a wind fam may vary in a remarkable and abrupt fashion in space and time under certain circunstances:

(a) Data time series of three towers on a line with common time axis. (b) Data time series at several levels at a tower with common time axis. 
1. The boundary-layer flow contains highly organized coherent perturbations with a typical size of $300 \times 300 \mathrm{~m}^{2}$.

2. The transition zones between the perturbations moving through a wind farm are associated with very definitive changes in the wind field that are on the order of meters and seconds. 


\section{CONTENTS}

SUMMARY , ................................ 1

1.0 INTRODUCTION $\ldots \ldots \ldots$

2.0 INSTRUMENTATION $\ldots \ldots \ldots$

3.0 MEASUREMENT RELIABILITY AND TOPOGRAPHIC INFLUENCE . * . * . * . . 5

3.1 FIELO INSTRIMENT INSTALLATION , . . . . . . . . . . 5

3.2 INSTRUMENT RESPONSE ..................... 5

3.3 SYNCHRONIZATION OF DATA ACQUISITION $\ldots \ldots \ldots \ldots$

3.4 TOPOGRAPHIC INFLUENCE $\ldots, \ldots \ldots$, $\ldots$

4.0 ANALYSES , ...............................9

4.1 ARE MAPS ABOVE GROUND LEVEL . . . . . . . . . . . . 9

4.2 LINE-TIME CROSS SECTIONS ................. 18

4.3 TOWER-TIME CROSS SECTIONS .................. 18

4.4 DIVERGENCE COMPUTATIONS .................. 24

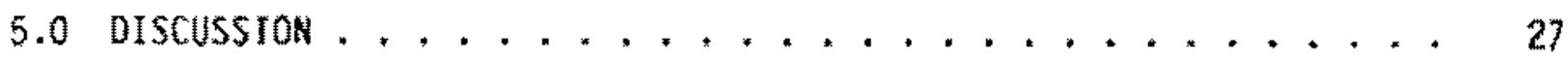

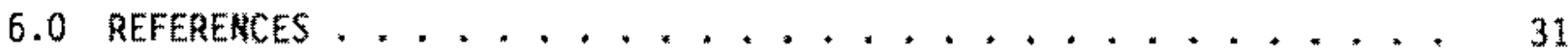




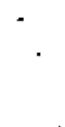




\section{FIGURES}

1 Goodnoe Hills Test Site with Three Turbines (T1, T2, and T3), the BPA and PNL Tall Towers, and the 32-m (105-ft) Portable Towers . . 2

2 Station Locations of $32 \mathrm{~m}$ Wind Measurements Used for Line-Time Cross Sections ..................... 7

3 Some Common Features observed in the Continuous Streamline Analys is

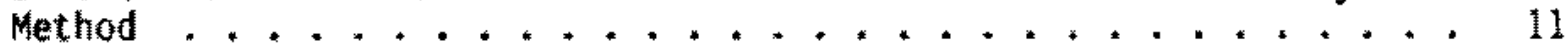

4 Area Maps for the Periods a) $1633: 21$ to i) $1634: 51$, June 27,1985 , Show Observations and the Analyses of the Eddy Vector Flow Field at $32 \mathrm{~m} \mathrm{AGL}$ at $10-5$ Intervals ................. 12

5 Area Maps for the Periods a) 1637:21 to j) 1638:51, June 27, 1985* . 15

6 Line-Time Cross Sections for the Period 1633:21 to 1634:51, June 27, 1985 , Show the Eddy Vector Flow Field at $32 \mathrm{~m} \mathrm{AGL} \mathrm{........} 20$

7 Line-Time Cross Sections for the Period 1637:21 to 1637:51, June 27, 1985, Show the Eddy Vector Flow Field at $32 \mathrm{~m}$ AGL . . . . . . 21

8 Vertical Time Cross Section for the PNL Tower for the Periods a) $1633: 20$ to $1634: 50$ and b) $1637: 20$ to $1638: 50$, June $27,1985 \ldots, 22$

9 Vertical Time Cross Section for the PNL Tower for the Periods a) 1632:10 to 1632:42, June 27, 1985, Showing a Counterclockwise (CC) Perturbation Ax is with a long Tail in the Lowest 15 in $(50-f t)$ Layer and b) 1637:34 to 1638:05, June 27, 1985, Showing a clockwise (c) Perturbation Axis with a Pronounced Outflow in all Layers. . . 23

10 The Resultant Component Flow Used for Divergence Calculations in a Triangle Formed by Observation Stations at Each Apex . . . . . . 25

11 Stability Conditions at the PNL Tower on June $27,1985 \ldots 28$ 


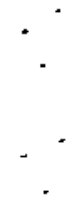




\subsection{INTRODUCTION}

During the windy season (summer) of 1985, a special wind-measuring project was conducted at the MOD-2 site at Goodnoe Hills, Washington. From June to September instruments on a configuration of seven $32-\mathrm{m}(105-\mathrm{ft})$ portable towers, in addition to the $107-\mathrm{m}(350-\mathrm{ft})$ Pacific Northwest Laboratory (PNL) and 59-m (195-ft) Bonneville Power Administration (BPA) tall towers, measured the horizontal wind. The two tall towers were equipped with the same instrumentation at the $32-\mathrm{m}$ level as the seven portable towers. The objectives of the field experiment were to provide data that would 1) allow detailed analyses of the spatial variability of the flow and 2) allow a closer examination of wake behavior from the three turbines reported by Elliott, Buck, and Barnard (1988). In both cases it was assumed that wind data sampled at 1-s intervals and averaged over 1-min intervals would be sufficient to perform such analyses. A subsequent objective was established to use the data collected to describe and depict small-scale perturbations traversing the site.

Although the analysis of 1-min average data had indicated the presence of small-scale perturbations in the basic flow, it was primarily the collection of a small sample of 1-s data that provided the opportunity for more intensive analyses for the identification and description of these perturbations. On June 27, 1985, 4 hours were set aside for recording 1-s data. There is a period of 8 min of $1-5$ data within these 4 hours that is undisturbed by turbine operation; i.e., turbines $\mathrm{T} 2$ and $\mathrm{T} 3$ are in the "off" mode. Turbine $\mathrm{T1}$, located to the east of the nine towers, ran during the whole 4 hours. It is assumed that its operation had no influence on the wind flow over the site, because the prevailing flow over the site during the 4 hours was from the westnorthwest. Figure 1 shows the layout of towers and turbines as well as the topography of the site.

This report discusses the analyses of the low-level flow (32 to $107 \mathrm{~m}$ ) over the Goodnoe Hills site during the 8-min period: 1632 to 1640 Local Standard Time (LST), June 27, 1985. 


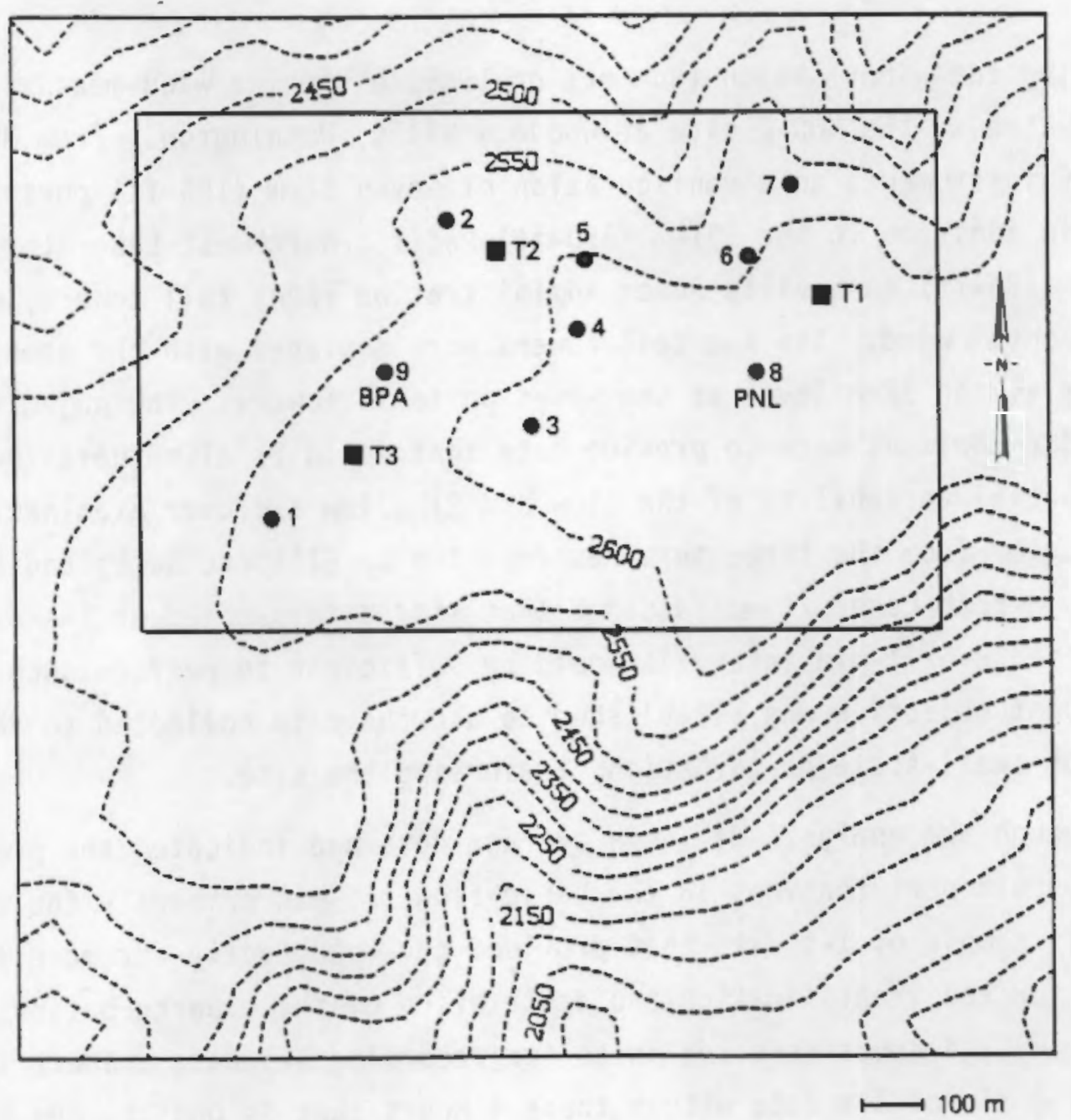

FIGURE 1. Goodnoe Hills Test Site with Three Turbines (T1, T2, and T3), the BPA and PNL Tall Towers, and the 32-m (105-ft) Portable Towers. The contour interval is $15 \mathrm{~m}(50 \mathrm{ft})$. 


\subsection{INSTRUMENTATION}

The PNL and BPA meteorological towers were installed in the beginning of the M0D-2 test program in 1982. Both of these towers had wind sensors at several levels, and the PNL tower had temperature sensors at selected levels (see Table 1). An additional seven $32-m$ portable towers were installed in June 1985 with instrumentation specifically to determine the variability of the horizontal flow at the site. Further information on the instrumentation is given in Table 1 .

TABLE 1. Instrumentation

\begin{tabular}{|c|c|c|c|c|}
\hline Tower & Level (m) & $\begin{array}{l}\text { Wind } \\
\text { Instrumentation } \\
\text { and Manufacturer }\end{array}$ & $\begin{array}{l}\text { Distance } \\
\text { Constant for } \\
\text { wind Speed } \\
\end{array}$ & $\begin{array}{r}\text { Other } \\
\text { Sensors }\end{array}$ \\
\hline \multirow[t]{2}{*}{ BPA Tower } & 15,59 & $\begin{array}{l}\text { Belfort, } \\
\text { Aerovane, } \\
120 \text { HD Type L. }\end{array}$ & $4.6 \mathrm{~m}$ & \\
\hline & 32 & $\begin{array}{l}\text { R. M. Young, } \\
\text { Anemometer Bivane } \\
\text { Model } 21003\end{array}$ & $0.8 \mathrm{~m}$ & \\
\hline \multirow[t]{2}{*}{ PNL Tower } & $\begin{array}{l}15,38 \\
61,84 \\
107\end{array}$ & $\begin{array}{l}\text { Climatronics, } \\
\text { Cup \& Vane Systen } \\
\text { Model F460 }\end{array}$ & $2.4 \mathrm{~m}$ & $\begin{array}{l}\text { Temperature at } \\
10,61,107 \mathrm{~m}\end{array}$ \\
\hline & 32 & $\begin{array}{l}\text { R. } M \text {. Young, } \\
\text { Anenometer Bivane } \\
\text { Model } 21003\end{array}$ & $0.8 \mathrm{n}$ & \\
\hline $\begin{array}{l}\text { Portable } \\
\text { Towers }\end{array}$ & 32 & $\begin{array}{l}\text { R. M. Young } \\
\text { Anemometer Biyane } \\
\text { Model } 21003\end{array}$ & $0.8 \mathrm{~m}$ & \\
\hline
\end{tabular}

(a) Sensors manufactured by Belfort Instrument Company, Alhambra, California; R. M. Young, Traverse City, Michigan; Climatronics, Glendale, California. 


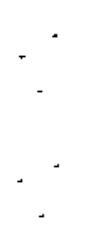




\subsection{MEASUREMENT RELIABILITY AND TOPOGRAPHIC INFLUENCE}

\subsection{FIELO INSTRUMENT INSTALLATION}

The seven towers were telescopic and supported by three sets of guywires. The instrumentation consisted of R. M. Young bivane anemometers. Every effort was made to avoid any deviation of alignment of tower and instrumentation from the vertical. It is therefore assumed that any alignment error would have been negligible and have no significant effect on the measurements. The same bivane sensors were installed on the PNL and BPA towers at the 32-m level and were relatively easy to align correctly using the tall towers and their other sensors as guides. The vertical angle obtained along with the measurement of the horizontal wind has not been used to correct or adjust the wind measurements.

\subsection{INSTRUMENT RESPONSE}

The PNL tower was equipped with Climatronics sensors at all levels except for the bivane installed at $32 \mathrm{~m}$. According to the manufacturer, these sensors have a distance constant of about $2.4 \mathrm{~m}$, which corresponds to a response time of about 0.2 to $0.3 \mathrm{~s}$ at a $10 \mathrm{~m} / \mathrm{s}$ wind speed. Since the data were acquired at a rate of one per second simultaneously at the original five levels, the response lag should have no significant effect on the 1-s measurements and even less on ayerages of 5 and 105 .

The instrumentation at the $32-m$ level throughout the site consisted of R. M. Young bivane sensors. According to the manufacturer, these sensors have a distance constant of about $0.8 \mathrm{~m}$, which corresponds to a response time of $0.1 \mathrm{~s}$ at a $10 \mathrm{~m} / \mathrm{s}$ wind speed. These sensors are therefore in the same response category as the Climatronic's sensors.

The belfort aerovanes on the BPA tower are the least sensitive sensors with a distant constant of $4.6 \mathrm{~m}$, corresponding to a response time of about $0.5 \mathrm{~s}$ at $\mathrm{a} 10 \mathrm{~m} / \mathrm{s}$ wind speed. However, the BPA tower measurements at the 15 and 59-m levels are only used to indicate the lack of synchronization of several seconds between the measurements at these two levels and those at the 32-m level on the tower (see section 3.3). 


\subsection{SYNCHROMIZATION OF DATA ACQUISITION}

An error that affects the measurements from the whole site is the lack of precise synchronization in time of their acquisition at the towers. Data from five levels $(15,38,61,84$, and $107 \mathrm{~m})$ on the PHL tower and two levels (15 and $59 \mathrm{~m}$ ) on the BPA tower are all recorded at the same time and are aiso synchronized along with the data from the three turbines on a central data acquisition system. However, in the nine-station array with bivanes at $32 \mathrm{~m}_{\text {; }}$ each sensor was equipped with its own Campbell Scientific CR-21X and cassette recorder completely independent of the other stations with no automated central coordination of measurements. This resulted in a discrepancy in timing, which will show up in any comparison analys is between data from different towers. unless averaging is done over periods longer than the intervals of the discrepancies.

The time difference between the acquisition of the data at the five leveis and that of the 32-m level on the PNL. tower is between 16 and $18 \mathrm{~s}$. This is clearly evident when comparing the two data sets in a time cross section. (a) Similarly, the difference between the 32-1il level and the other two levels on the BPA tower is on the order of 8 to 105 . Unfortunately, data from the other seven towers cannot be checked out in a similar way. Therefore, when comparing observations and their anomalies from these towers, we must use averages of I-s data on the area maps $32 \mathrm{~m}$ above ground level (AGL) and in the three line cross sections shown schenatically in Figure 2. Because the time differences between the two sets of sensors on each of the two tall towers are on the order of 10 to $20 \mathrm{~s}$, it is assumed that the data systems on the portable towers are off by a similar amount. This difference indicates that means of $20 \mathrm{~s}$ or longer for the computation of anomalies should be used. However, to preserve important details in the flow that appear at each individual tower and also to obtain as many "snapshots" as possible of the traveling perturbations, 10-s means have been used. Occasionally, therefore, it is difficult to fit seemingly "odd anomalies" into a smooth analysis. This problem does not occur in the PNL tower time cross section of the five original

(a) Series of data at several levels with comon time axis. 


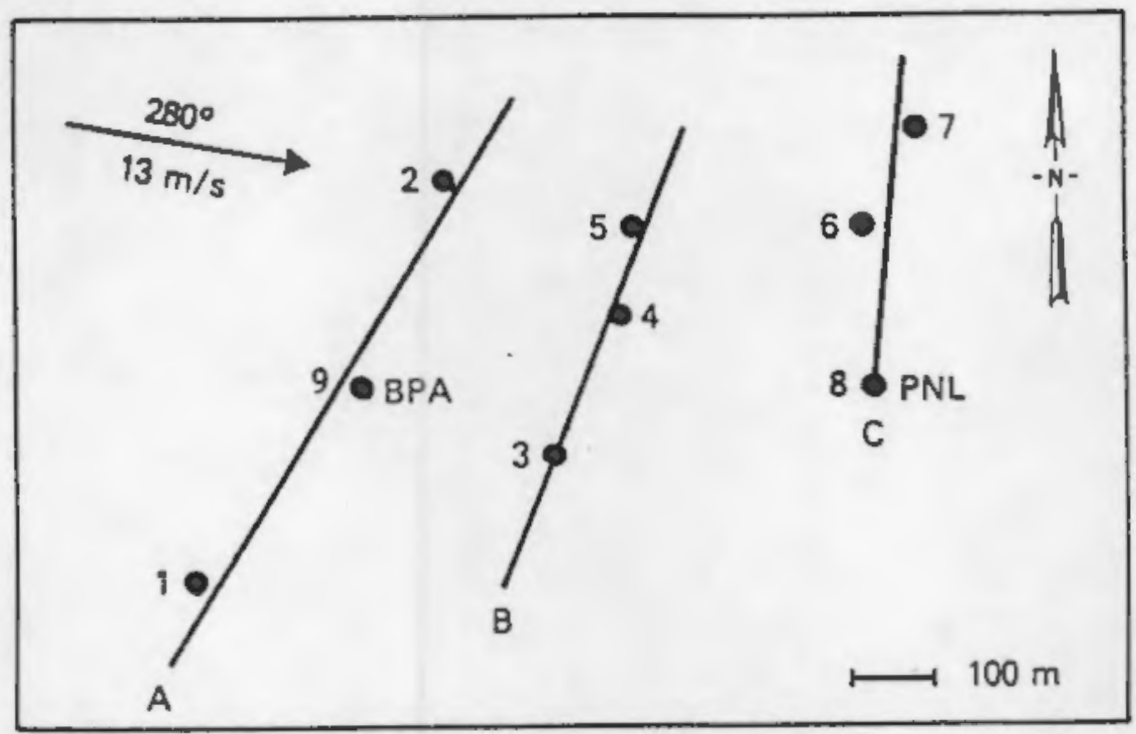

FIGURE 2. Station Locations of 32-m Wind Measurements Used for Line-Time Cross Sections. A: $2-9-1 ; B: \quad 5-4-3 ;$ and $C: \quad 7-6-8$

levels; these provide a beautiful example of how observations fit perfectly together when all observations are precisely synchronized.

\subsection{TOPOGRAPHIC INFLUENCE}

The Goodnoe Hills site is part of a high plateau with several gullies cutting in on its sides. Some gullies are more pronounced than they appear in Figure 1. The only vegetation is sagebush except in the northeastern corner of the site, where there are some trees in one of the gullies. When the wind is from the northwest these trees create a sheltering effect downwind, which modifies the wind conditions at stations \#6 and especially \#7 (Elliott and Barnard 1990). This sheltering effect is also notably enhanced by the gully to the west of those stations. As a result, when well-developed vortices pass over this area, the wind speed decreases considerably (the anomalies show strong easterly components) while the wind direction is much less affected. The mean wind speed at the \#7 site is about 4 to $4.5 \mathrm{~m} / \mathrm{s}$ less than that for the rest of the site, while its mean wind direction deviates only a few degrees from that of the general mean direction for the site. 



\subsection{ANALYSES}

The analysis techniques that have been applied in this boundary-layer study are generally considered to be unconventional for use on this scale of motion. The most common representation of turbulence in the wind on scales of meters and seconds is a spectral function derived from the Fourier transform of a time series of the wind components. Such representations provide valuable insight into the periodic components that make up a time series. Additional insight into the nature of turbulent eddies in the boundary layer can be achieved by direct analysis of the wind data in the time and space domain.

Throughout this work perturbations or anomalies in the flow are derived from the instantaneous and mean wind. These are defined respectively for the east-west and north-south wind components, $u^{\prime}=u-\bar{u}$ and $v^{\prime}=v-\bar{v}$ where

$$
\bar{u}=\frac{1}{\Delta t} \int_{t-\frac{\Delta t}{2}}^{t+\frac{\Delta t}{2}} u d t .
$$

The length of the time increment, $\Delta t$, is $8 \mathrm{~min}$. It is based on the availability of a wake-free data series with respect to turbine operation. In this application, the 8 -min mean values represent the main underlying free flow.

\subsection{AREA MAPS ABOVE GROUND LEVEL}

Using data from the portable towers, we have computed anomalies and displayed them on areal maps at $32 \mathrm{~m} \mathrm{AGL}$. Discrepancies in the continuity of the flow moving across the site are unavoidable because the stations were not precisely synchronized. Anomalies of 10-5 mean velocity data have been used to provide a smoother comparison of measurements from the nine stations and for direct verification of eddy features in conjunction with the line-time and tower-time cross sections.

The relative velocity vectors have been presented as direction in decadegrees and speed in tenths of miles per hour (multiply by 0.447 to get tenths 
of $\mathrm{m} / \mathrm{s}$ ). The continuous streamline method has been used to analyze the data. In this method the flow vector is represented by two scalar fields: isotachs (lines of equal speed) and streamlines (lines parallel with the flow). Several features that may repeatedly manifest themselves in such an analysis are shown in Figure 3.

The area maps show the 10-s mean anomalous flow for each station at 10-5 intervals. The $10-\mathrm{s}$ mean covers the 10 consecutive observations from, for example, 1632:01 to 1632:10, and is plotted at 1632:01. A station's anomaly velocity vector for a 10 -s period is represented by

$$
A_{i, j}=S_{i, j}-S_{i}
$$

where $S=$ horizontal wind measurement, $i=1$ to 9 stations, $j=1$ to $4810-\mathrm{s}$ periods, and the bar in the last term indicates an average over all 48 10-s intervals.

During the 8-min period there were several counterclockwise (CC) and clockwise (C) circulation systems in the lower boundary layer that passed the Goodnoe Hills test site. Two map series, shown in Figures 4 and 5 , have been selected as illustrations. They are marked as $C C_{j}$ or $C_{i}$, where $i$ is the number of one of the consecutively numbered perturbations occurring during the total period. Several of the perturbations occurred as complete vortices while others appeared as waves (troughs and ridges) with less well developed features. They traversed the site from WNW to ESE approximately in the mean direction $\left(280^{\circ}\right)$. Their speed varied but was in all cases equal to or greater than the average for the site $(13 \mathrm{~m} / \mathrm{s})$. 
Vortices:
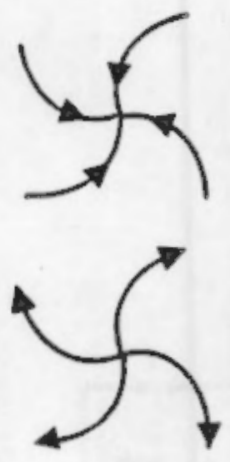

Cusps:
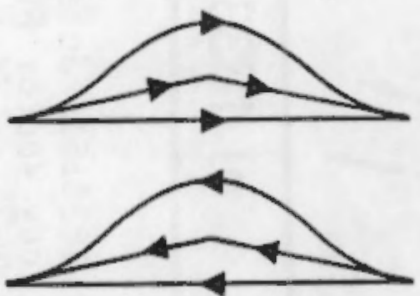

Neutral Point:

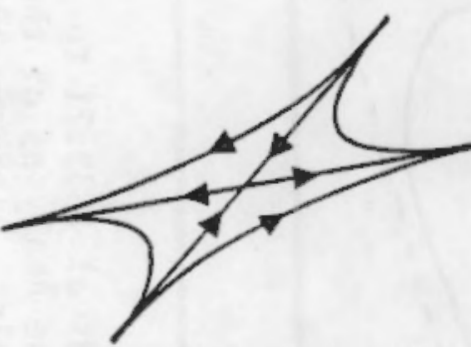

Asymptotes:
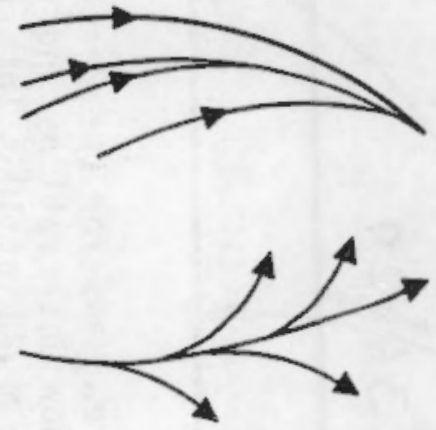

Counterclockwise Inflow Center

Clockwise Outflow Center

Occurring When Vortices

Develop or Decay

\section{A Neutral Point Must Always Accompany a Vortex}

Asymptote of Confluence

Asymptote of Difluence

Note: Confluence and difluence are not the same as convergence and divergence. Both the streamline and isotach fields are necessary to determine the latter.

FIGURE 3. Some Common Features Observed in the Continuous Streamline Analysis Method 


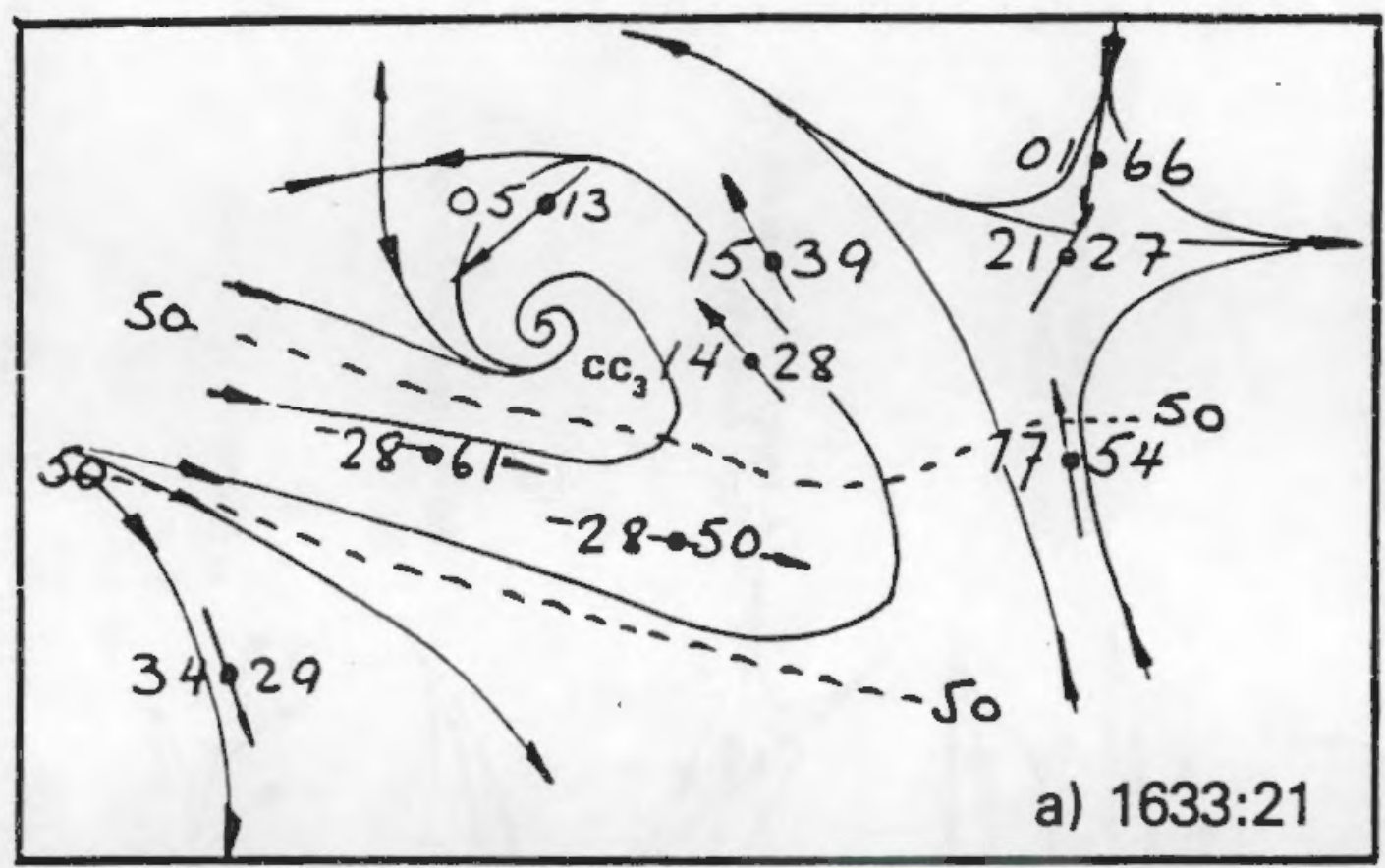

FIGURE 4. Area Maps for the Periods a) 1633:21 to i) 1634:51, June 27, 1985, Show Observations and the Analyses of the Eddy Vector Flow Field at $32 \mathrm{~m} \mathrm{AGL}$ at 10-s Intervals. Data are 10-s average of 1-s measurements. Wind direction is in decadegrees $\left(28=280^{\circ}\right)$, and wind speed is in tenths of miles per hour $(61=6.1 \mathrm{mph})$. Solid lines are streamlines, dashed lines (--) are isotachs in tenths of miles per hour. Only major isotachs are shown. Vortex centers and cusps are indicated with $\mathrm{C}$ or $\mathrm{CC}$. To convert tenths of $\mathrm{mph}$ to $\mathrm{m} / \mathrm{s}$, multiply the speed value by 0.447 . 

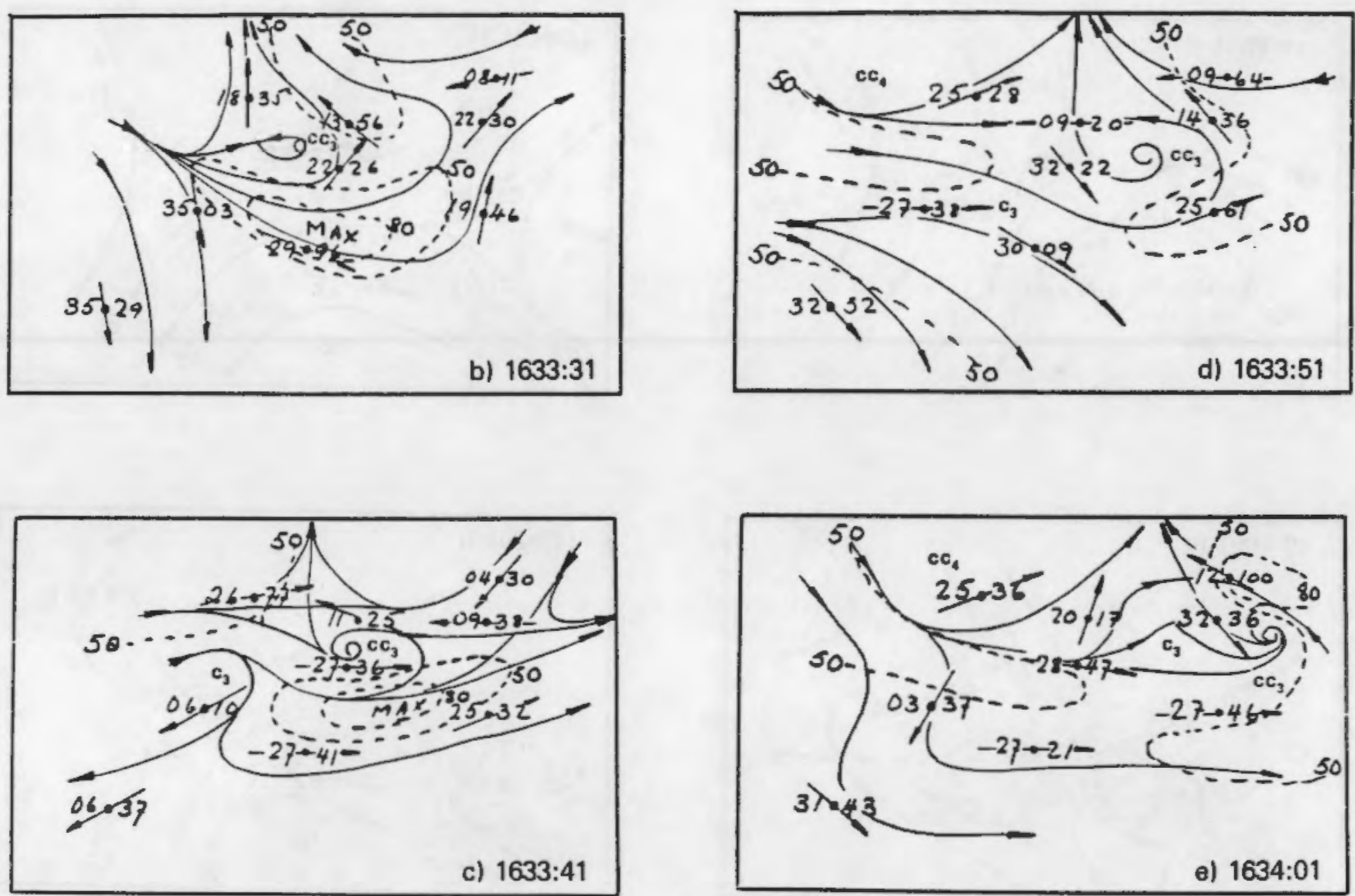

FIGURE 4. Continued 

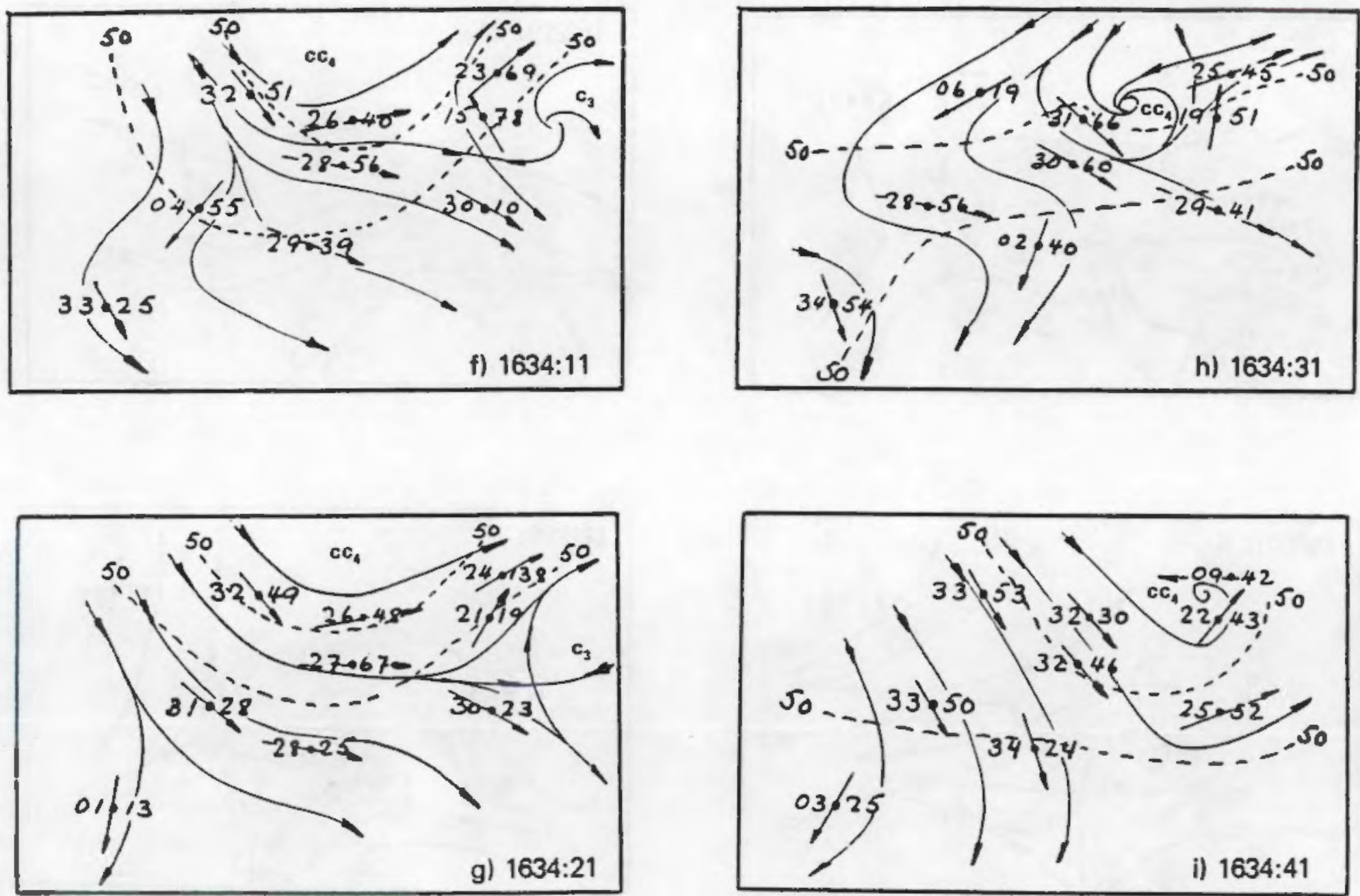

FIgURE 4. Cont inued 

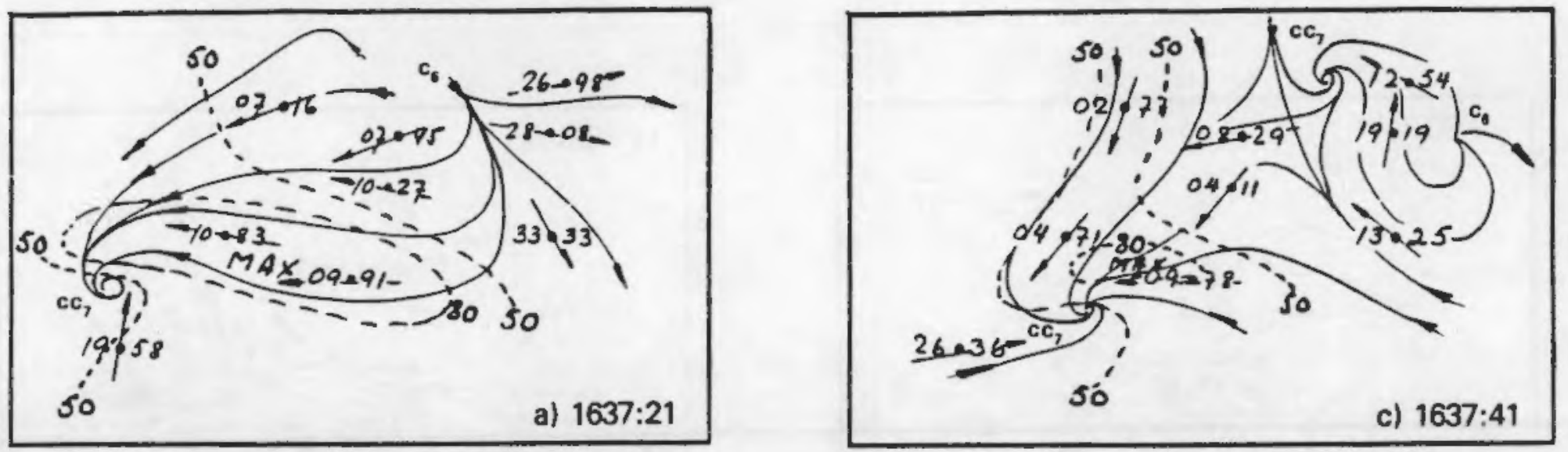

它
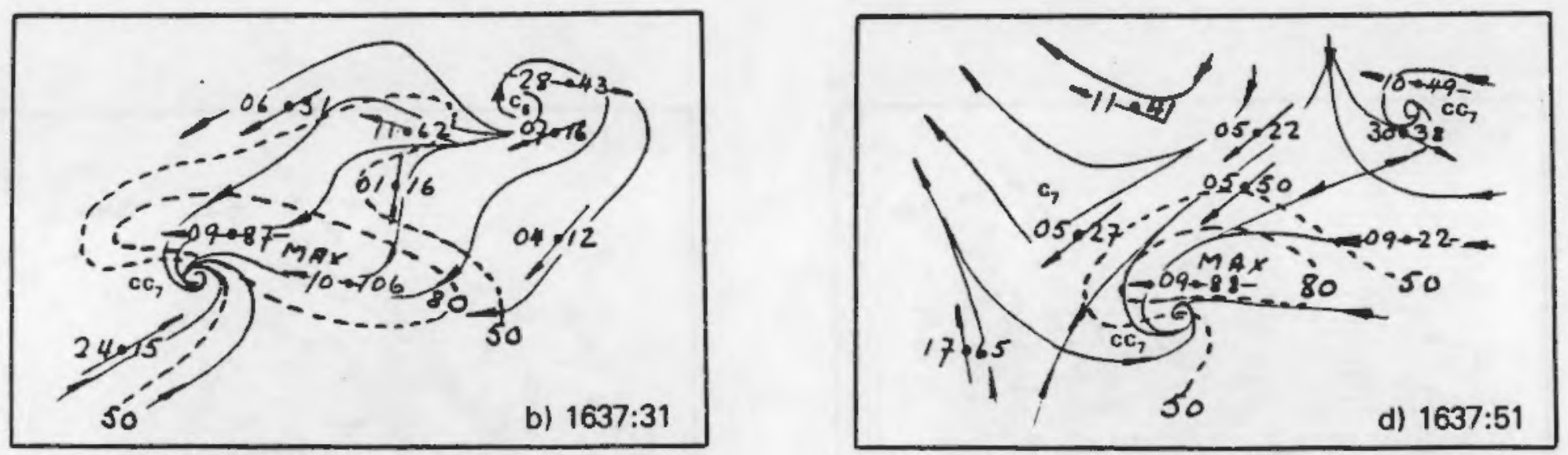

FIGURE 5. Area Maps for the Periods a) 1637:21 to j) 1638:51, June 27, 1985. (See Figure 4 for detail.) 

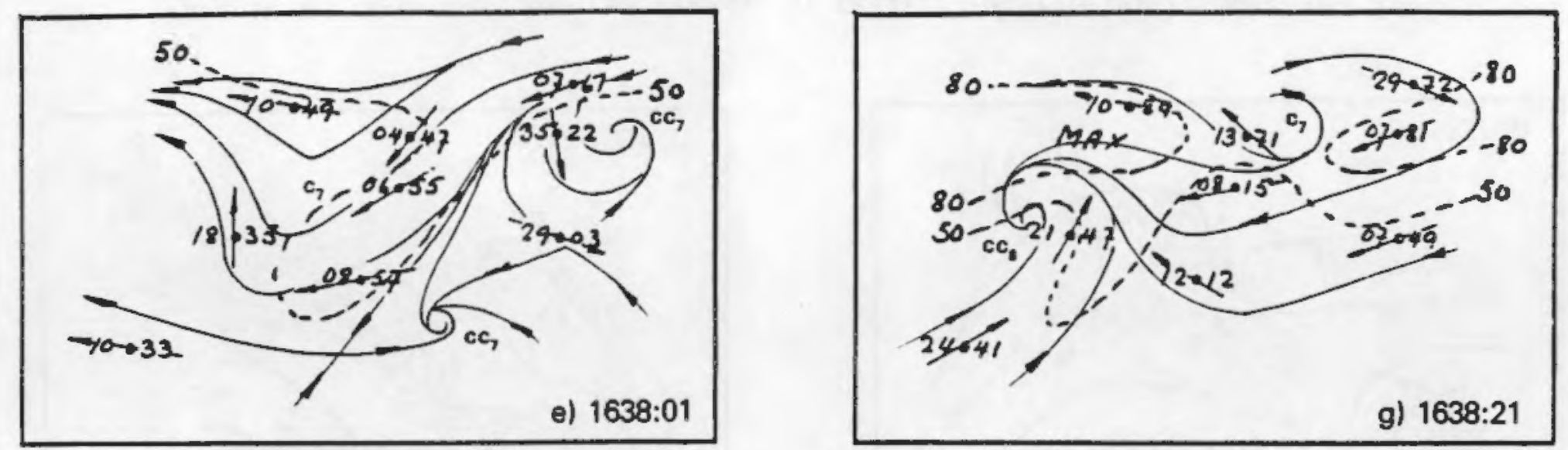

का
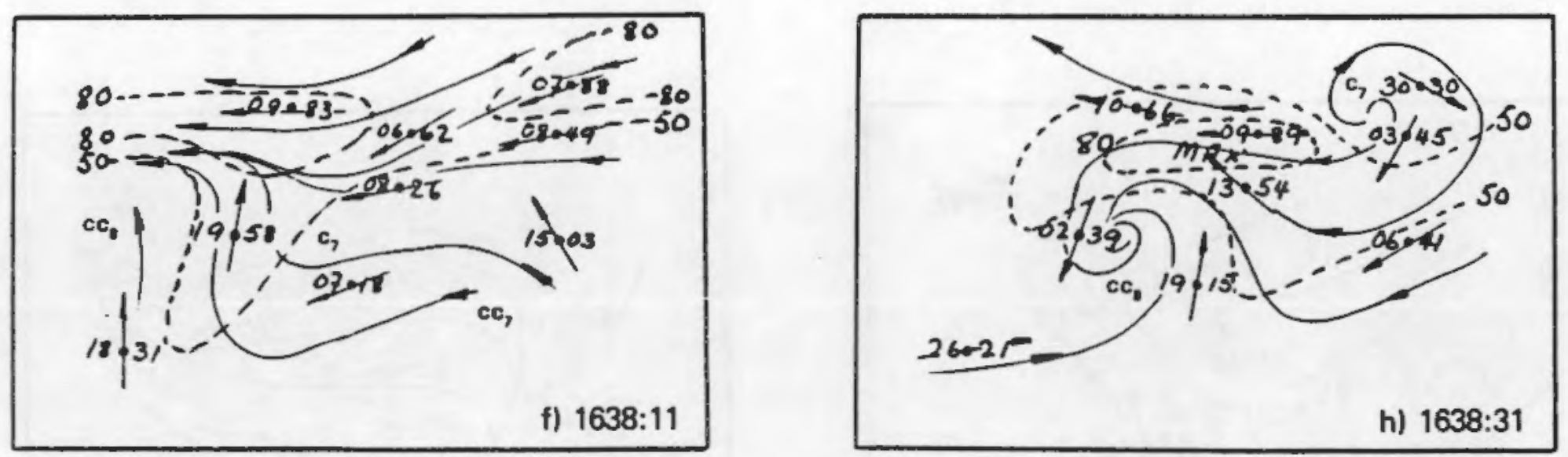

FIGURE 5. Continued 


\subsection{LINE-TIME CROSS SECTIONS}

The 32-m towers are arranged in such a way with respect to the prevailing wind direction that they may be used in line-time cross sections. The three line cross sections and the prevailing wind conditions for the analysis period were shown in Figure 2. The cross sections for the three lines are plotted on maps (Figures 6 and 7) such that A (top), B (middle), and C (bottom) represent the anomalies at stations 2-9-1, 5-4-3, and 7-6-8. Although the values plotted for each station and line are the same as those found on the area maps (shown in Figures 4 and 5 ), it is generally easier to follow the movements of the various kinematic features when the cross sections are presented with a common time axis as shown in Figures 6 and 7 . The time axis increases to the left so that the features passing through the lines from the west are not distorted from their basic shape and appearance. To depict disturbances moving from east to west, the time axis should point to the right. Most perturbations traversing the site will pass through all three lines. However, there are exceptions. Any eddies that enter line A south of station 9 will most probably not show up at lines B and C. Similarly, eddies may show up at stations 6 and 7 without having been noticed earlier at stations to the west thereof.

\subsection{TOWER-TIME CROSS SECTIONS}

Wind data from five permanent and synchronized levels $(15,38,61,84$, and $107 \mathrm{~m}$ ) on the PNL tower were used to produce vertical time cross sections. The plotted departures of the horizontal winds show the structure of the wave perturbations as they move through the tower. The computed departures are shown at intervals of $10 \mathrm{~s}$ in Figure 8 and $1 \mathrm{~s}$ in Figure 9. The 10-s interval represents a mean of 10 sequential measurements, and the total averaging period, in both cases, is $8 \mathrm{~min}$ or $480 \mathrm{~s}$. Thus,

$$
A_{i, j}=L_{i, j}-\bar{L}_{\mathbf{i}}
$$

where $J=1$ to 480 for $1-s$ intervals and 


$$
A_{i, j}=L_{i, j}-\bar{L}_{i}
$$

where $\mathbf{j}=1$ to 4810 -s periods

$L=$ horizontal wind vector measurements at a level $i=1$ to 5 .

To display the horizontal wind anomalies from the tower data in a twodimensional format, the data are plotted in the same format as that used for a conventional vertical time section. The vertical axis on the plot represents both height above ground and the north-south wind direction for plotting the horizontal wind vectors. The time axis is pointing to the left for the same reason as mentioned under line-time cross sections (Figures 6 and 7 ).

For ease of comparison with the horizontal maps, the $32-m$ level has been marked on the tower time sections shown in Figure 8, although the data for this level are not plotted. The disturbances or parts thereof that actually passed the tower during the 8-min period were seven counterclockwise and eight clockwise entities and, as is observed on much larger scales, they occurred in pairs. The size of a vortex is easiest to estimate using the line cross sections of the type shown in Figures 6 and 7 . With a $15 \mathrm{~m} / \mathrm{s}$ speed, they are about $300 \times 300 \mathrm{~m}^{2}$, although they vary in size. The perturbation axes slope with height in the direction of their movement. The range of the slope is between $1 / 3$ and $1 / 6$. This slope is due to drag against the lower boundary, so that an axis may have a long tail in the lowest 50 to $100 \mathrm{~m}$ as is shown in Figure 9a. All of the perturbation axes are concave in shape, indicating that the slope may reverse with height above our observation layer. Similar slopes are also evident in the north-south direction; that is, all perturbations that passed north of the PNL tower show up in the tower-time cross sections, while the few (about $30 \%$ ) that passed south of the tower do not.

In the 1-s time cross sections shown in Figure 9, the perturbations and their axes are even more pronounced than in the 10-s mean sections. The width of an axis is on the order of $10 \mathrm{~m}$ or less. The same is valid for asymptotes and shear lines. The wind may change considerably across such lines over a relatively short time; for example, in Figure 9a the anomalies at 1632:28 at $15 \mathrm{~m}$ are $240 / 1.1 \mathrm{~m} / \mathrm{s}$ and $5 \mathrm{~s}$ later $060 / 2.0 \mathrm{~m} / \mathrm{s}$, a $3.1 \mathrm{~m} / \mathrm{s}$ change; or at 1632:24 $230 / 2.3 \mathrm{~m} / \mathrm{s}$ and $13 \mathrm{~s}$ later $080 / 3.7 \mathrm{~m} / \mathrm{s}$, a $6.0-\mathrm{m} / \mathrm{s}$ change. The change in the 


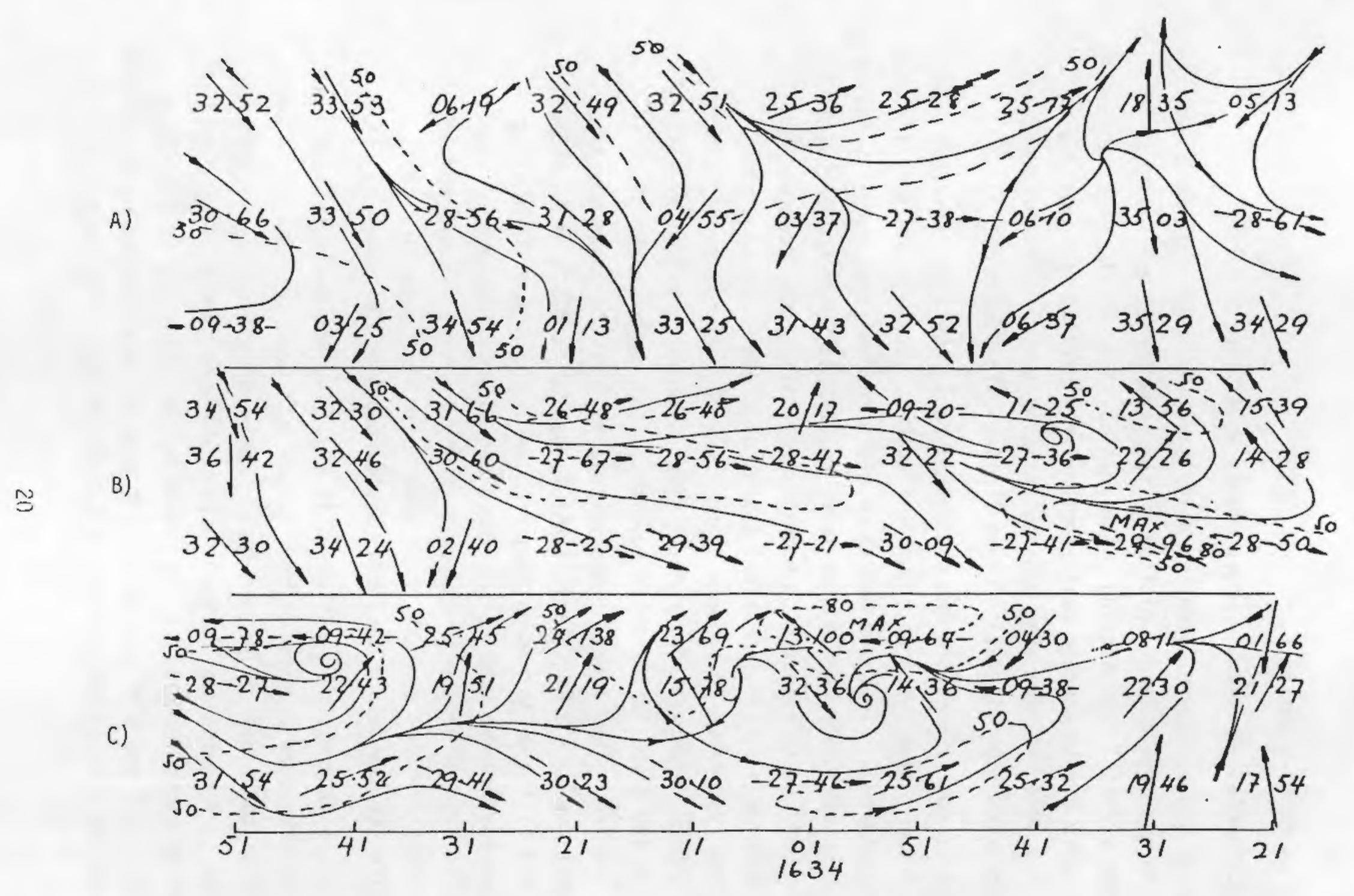

FIGURE 6. Line-Time Cross Sections for the Period 1633:21 to 1634:51, June 27, 1985, Show the Eddy Vector Flow Field at $32 \mathrm{~m} \mathrm{AGL}$. The top shows the time section for Line $A$ in Figure 2, the middle for Line B, and the bottom for Line C. The data and notation are the same as on the areal maps. See Figure 4 for explanation of direction and speed notation. 
A)

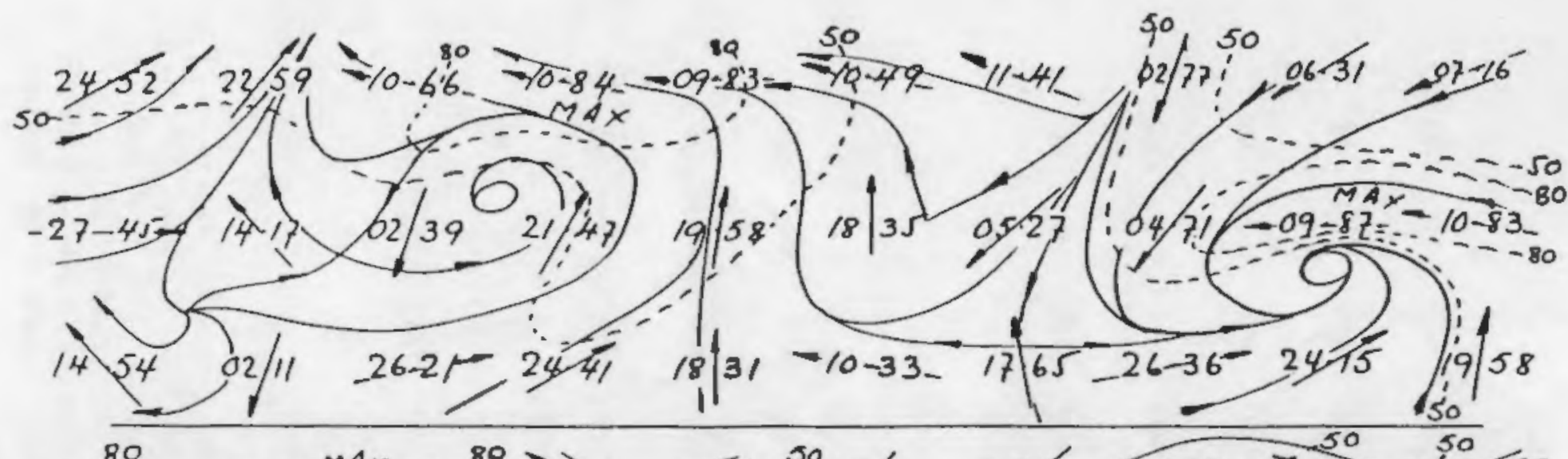

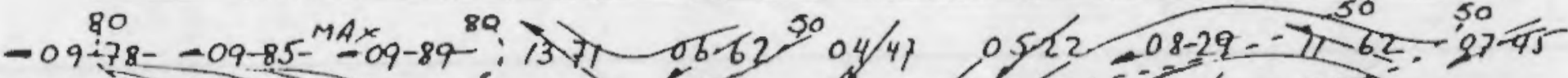

$5006351259-1354-88-75=08-26 / .0655$

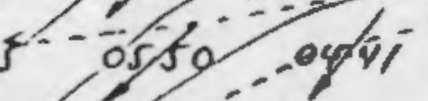

$0116=102 z$

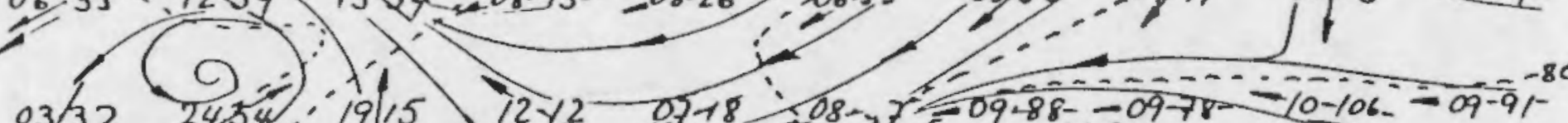

$03 / 32$

50 -

so

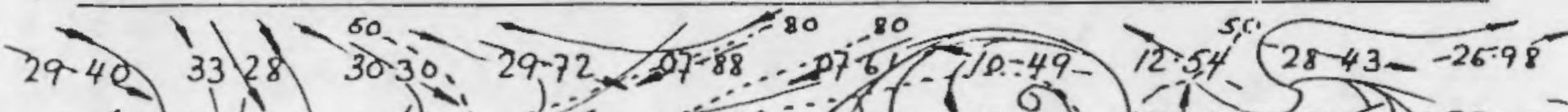

c)

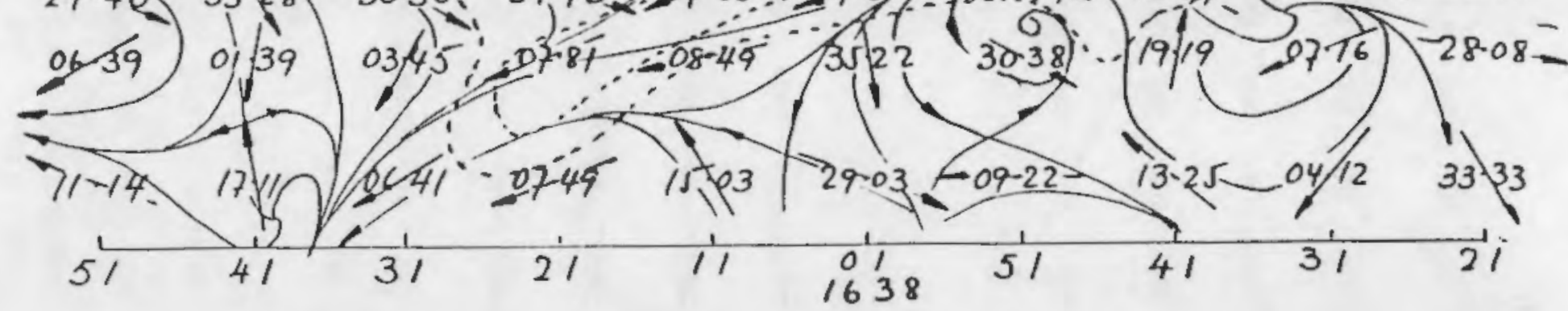

FIGURE 7. Line-Time Cross Sections for the Period 1637:21 to 1638:51, June 27, 1985. See Figure 6 for detail. 

TURBULENT EDDY VECTORS - PNL TOWER, GOODNOE HILLS, WA

a)

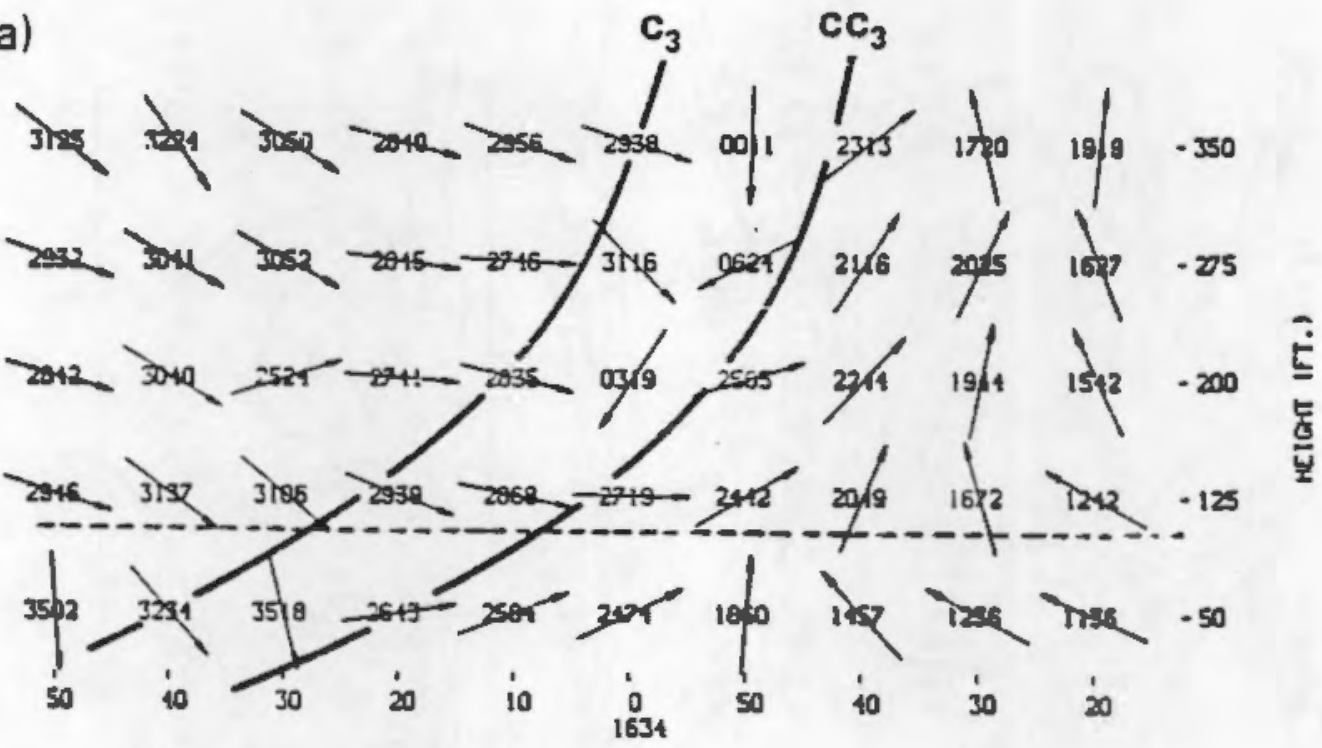

- TIRE

b) $\quad \mathrm{Cc}_{7}$

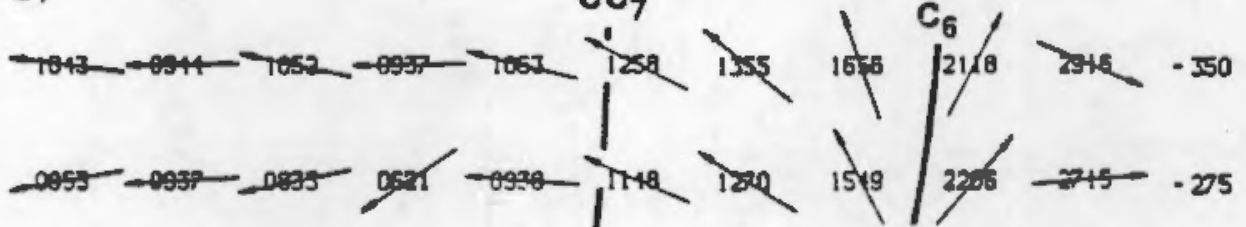

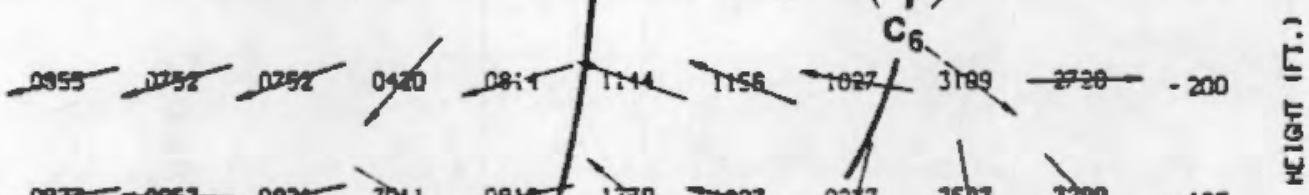

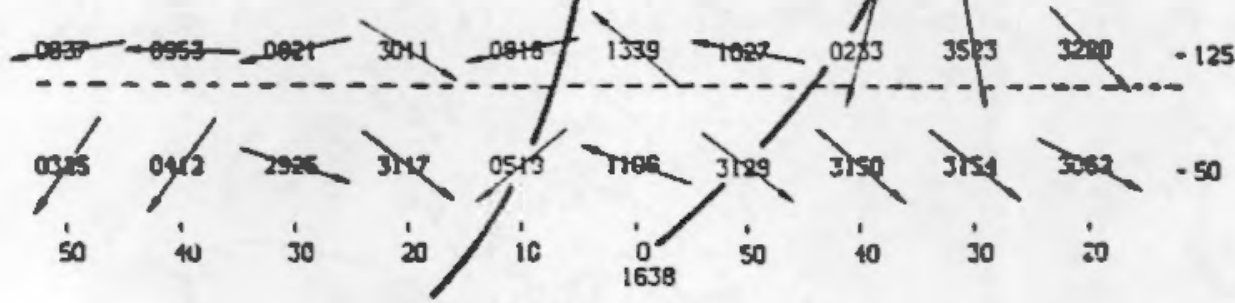

FIGURE 8. Vertical Time Cross Section for the PNL Tower for the Periods

a) 1633:20 to $1634: 50$ and b) $1637: 20$ to $1638: 50$, June 27,1985 . Data are $10-5$ averages of $1-5$ measurements. The $32-m$ level is indicated with a thin dashed line, perturbation axes with heavy solid lines, and clockwise and counterclockwise circulations with $C$ and $C C$, respectively. (See Figure 4 for explanation of speed and direction rotation.) 


\section{TURBULENT EDDY VECTORS - PNL TOWER, GOODNOE HILLS, WA}

a)

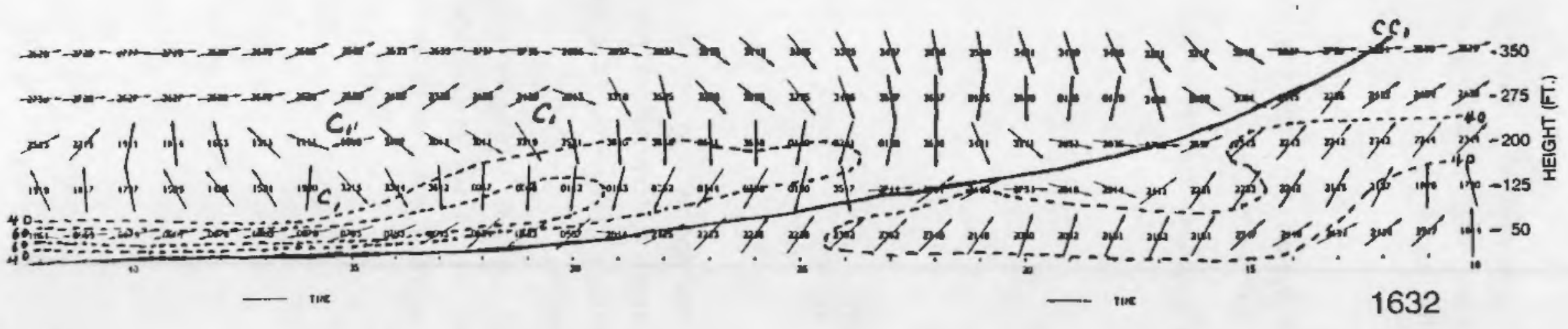

b)

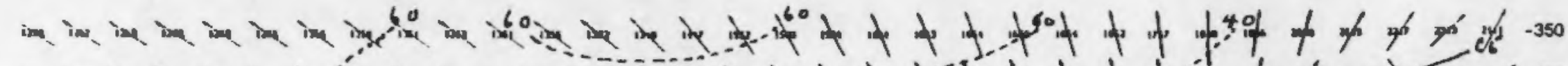

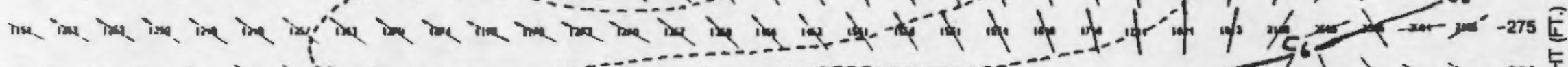

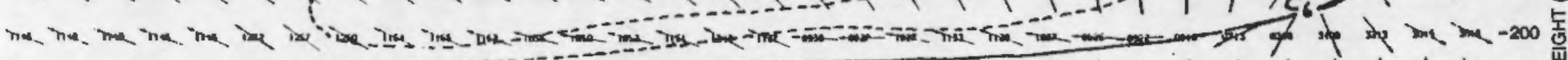

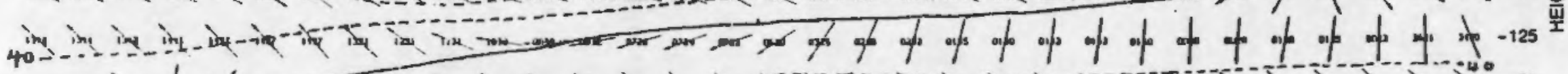

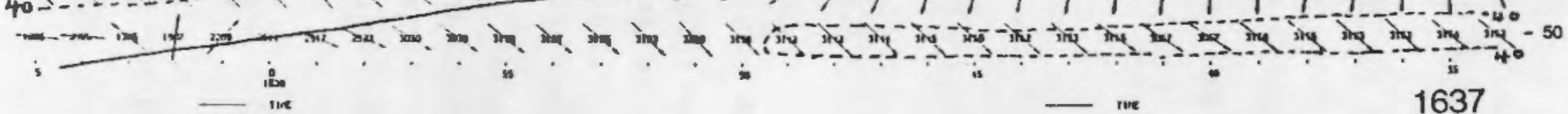

FIGURE 9. Vertical Time Cross Section for the PNL Tower for the Periods a) 1632:10 to 1632:42, June 27, 1985. Showing a Counterclockwise (CC) Perturbation Axis with a Long Tail in the Lowest 15-m (50-ft) Layer and b) 1637:34 to 1638:05, June 27, 1985, Showing a Clockwise (C) Perturbation Axis with a Pronounced Outflow in all Layers. Data are 1-s measurements, solid lines are axes, and dashed lines are isotachs for 4 and $6 \mathrm{mph}$,
i.e. 1.8 and $2.7 \mathrm{~m} / \mathrm{s}$. 
direction in the total wind would of course be very small, but the relative wind goes from a "surplus" (westerlies) to a marked "deficit" (easterlies) after the passage of the line, which lasts for about $10 \mathrm{~s}$.

\subsection{DIVERGENCE COMPUTATIONS}

To obtain a better understanding of the dynamics of the traveling eddies, velocity divergence computations have been carried out.

Using the mass continuity equation and assuming incompressibility, we write

$$
\nabla \cdot \vec{v}=-\frac{1}{\rho} \frac{\mathrm{d} \rho}{\mathrm{d} t}=0
$$

and the horizontal velocity divergence is

$$
\nabla_{H} \cdot \vec{v}_{H}=\frac{\partial u}{\partial x}+\frac{\partial v}{\partial y} \quad .
$$

Notation is conventional.

The Goodnoe Hills tower site has been divided into triangles with a tower in each apex. The net inflow/outflow (convergence/divergence) has been calculated for each triangle. The order of magnitude of $\nabla_{H} \cdot V_{H}$ is a direct function of the length of the sides of the triangle.

Example: Triangle 1 is formed by Stations 1, 3, and 9 (Figure 10). Calculate the components of the flow at each apex, which are perpendicular to each side and their resultants ( $R$ ). The sum of $u$ and $v$ components at respective apexes for each side is

$$
\begin{aligned}
& R_{1}(u)=\frac{u_{1}+u_{9}}{2} \cos 41 \cdot D_{19} \\
& R_{1}(v)=\frac{v_{1}+v_{9}}{2} \cos 49 \cdot D_{19}
\end{aligned}
$$




$$
\begin{aligned}
& R_{2}(u)=\frac{u_{1}+u_{3}}{2} \cos 73 \cdot D_{13} \\
& R_{2}(v)=\frac{v_{1}+v_{3}}{2} \cos 17 \cdot D_{13} \\
& R_{3}(u)=\frac{u_{3}+u_{9}}{2} \cos 69 \cdot D_{39} \\
& R_{3}(v)=\frac{v_{3}+v_{9}}{2} \cos 21 \cdot D_{39}
\end{aligned}
$$

and

$$
\text { Div }=\frac{R_{2}(u)-R_{1}(u)+R_{3}(u)+R_{1}(v)-R_{2}(v)+R_{3}(v)}{\text { Triangle Area }} \text {. }
$$

See Figure 10 for definition of terms.

There are, of course, other ways of doing the divergence calculations. However, they are all based on the same flow observations so that the end results are practically the same regardless of which method is used.

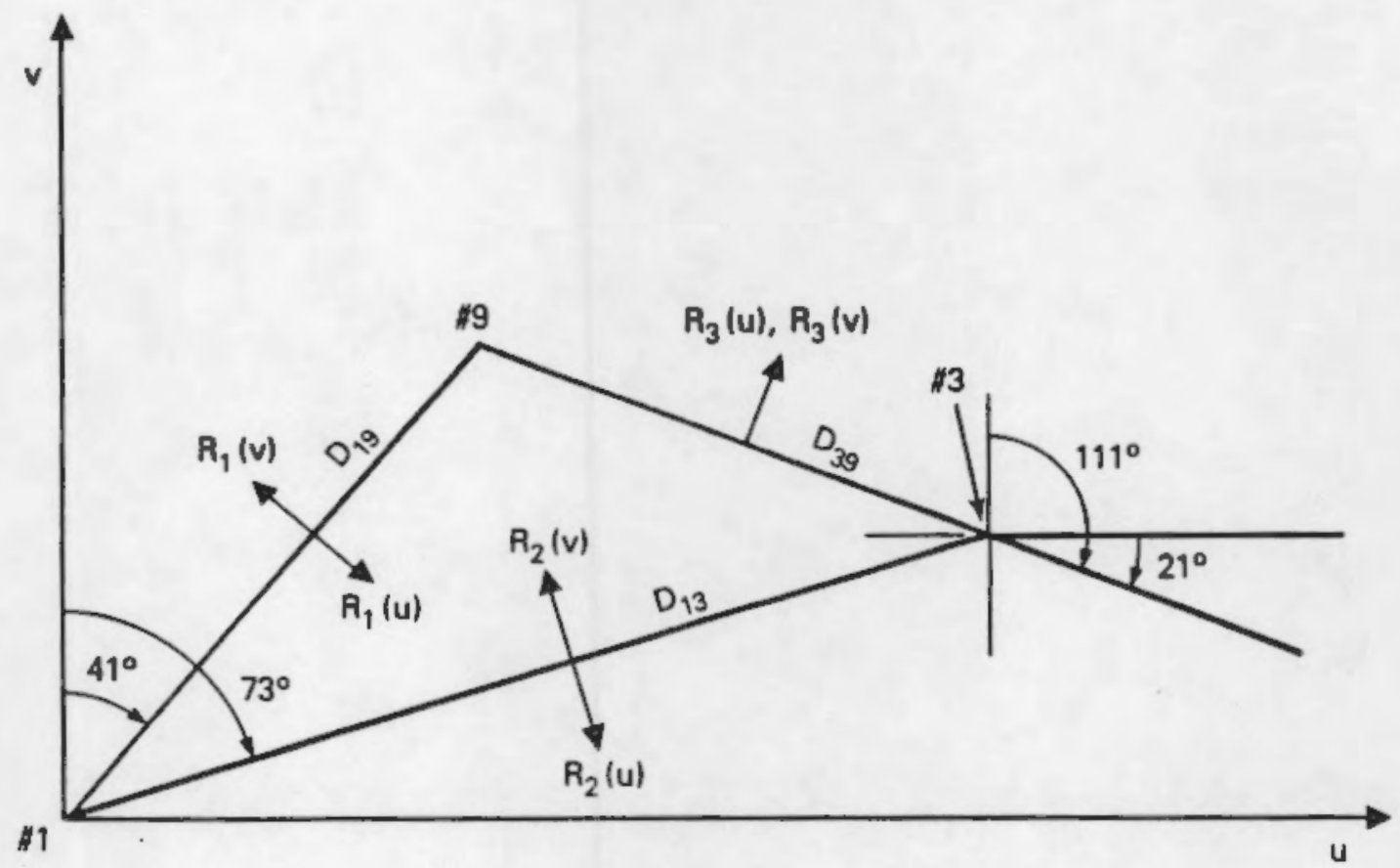

FIGURE 10. The Resultant Component Flow Used for Divergence Calculations in a Triangle Formed by Observation Stations at Each Apex 
The divergence computations resulted in values on the order of $\pm 10^{-2} \mathrm{~s}^{-1}$. This is in agreement with the size of the triangles whose sides run from about 100 to $450 \mathrm{~m}$. In comparing the divergence values with the area maps above ground level, it was found that the areas dominated by clockwise circulations show divergence, and counterclockwise circulations show convergence. The strongest convergence areas, about $-5 \times 10^{-2} \mathrm{~s}^{-1}$, happen to the west and south of the easterly maximum in the isotach field. 


\subsection{DISCUSSION}

The most noticeable characteristics in the space-time analyses of the eddy flow in the boundary layer at the Goodnoe Hills site are the organization and order. The coherent structure of the perturbations is quite evident in spite of the stochastic appearance of the wind speed time series at individual observation points. Several features and pattems common to much larger scales of motion, such as frontal discontinuities, appear to be imbedded in the flow over the site.

The flow is dominated by wave motion. This is displayed in a 3-D array of clockwise and counterclockwise circulations at $32 \mathrm{~m} \mathrm{AGL}$. Their horizontal arrangenent is lllustrated on the areal maps and line-tine cross sections, and their vertical extent is shown in the PNL tower-time cross sections. How far these wave systems extend horizontally and vertically is not known, but they are large enough and have existed long enough for the corjolis effect to have an explicit impact on the flow.

A sumnary of the measurements from the three temperature sensors on the PAL tower is shown in Figure 11 for June 2\%, 1985. The numbers indicate 10-min averages of the temperature lapse rate in two layers between 10 and $107 \mathrm{~m}$. There exists a superadiabatic lapse rate in the lower layer and stability in the upper layer during the observation period. This is a comon situation in large areas of this part of the united States during daylight hours in the summer when weather is undisturbed. These conditions are ideal for wave development in the boundary layer. Buoyancy is easily released at the surface and the upper stable layer acts as a damper on further upward penetration.

The divergence calculations show that the waves at $32 \mathrm{~m}$ AGL are associated with a definite pattern of vertical motion. If the divergence does not change sign between the surface and $32 \mathrm{~m}$, in agreenent with the size of the calculated values of inflow and outflow in this layer, convergence is associated with upward motion and positive divergence with downward motion. The vertical motion at 32 in is about \pm 1 to $2 \mathrm{~m} \mathrm{~s}^{-1}$.

The temperature time series were also used to calculate departures from the mean at each recorded level. The negative departures were largest at $10 \mathrm{~m}$ and decreased toward $107 \mathrm{~m}$. At the lower level they exceeded $-0.5^{\circ} \mathrm{C}$. 


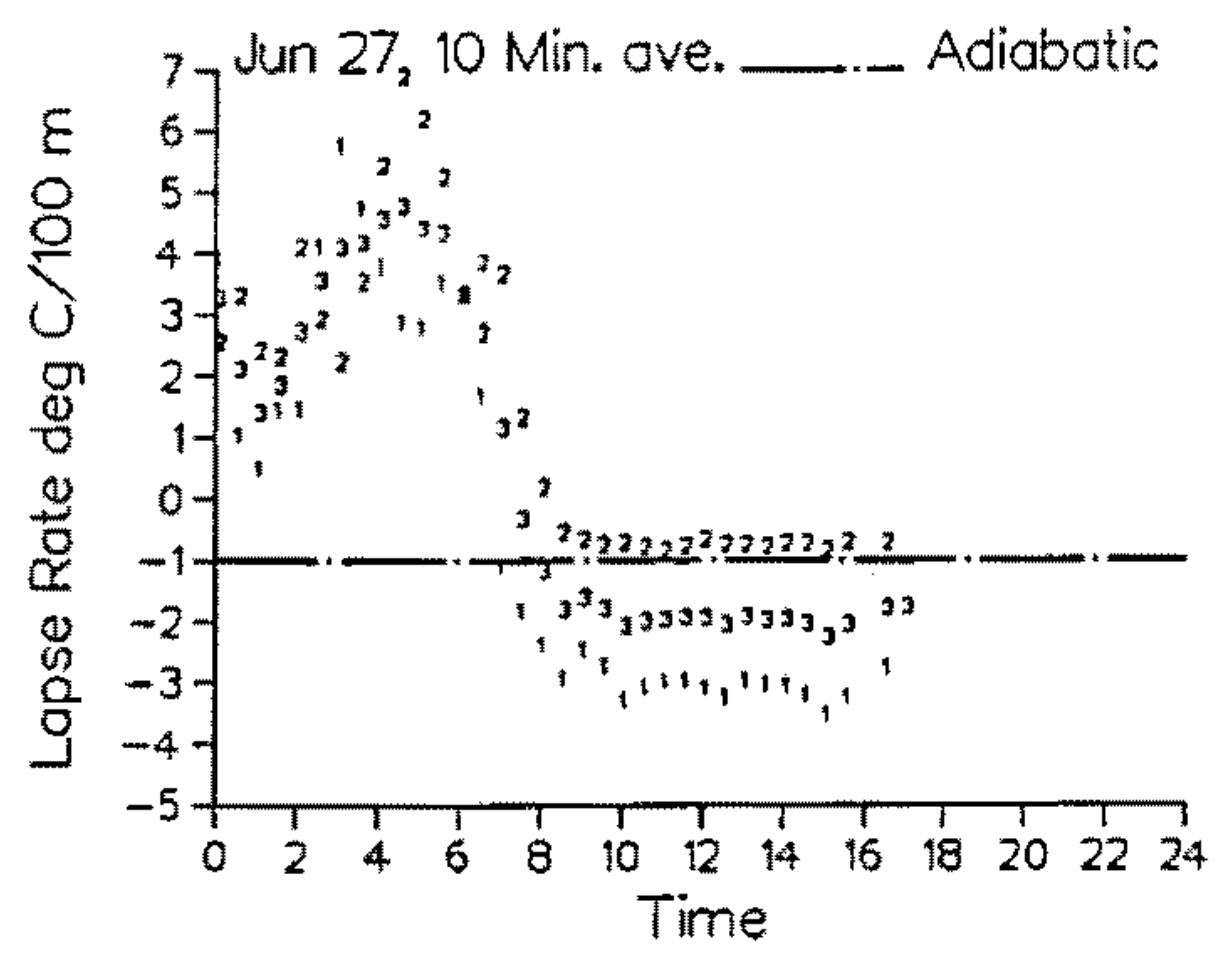

F1GURE 11. Stability Conditions the PNL Tower on June 27, 1985. Ten-minute averages of temperature measurements at 10, 61, and 107 are used to obtain lapse rates: $1=T 61-710 ; 2=1107-761$, and $3=1107-110$. The horizontal dotted line is the adiabatic lapse rate.

These pockets with relatively less heat energy occur in areas with divergence and thus confirm that relatively cooler air was brought downwards adiabatically:

The major function of the wave systems is to act as an exchange mechanism of energy, such as heat and nomentum, to smooth out gradients between layers. This in turn serves to minimize any shear $z$ mes for the benefit of a more uniform rotor operation and power output. These conditions are also likely to facilitate the extraction of wind energy at several levels. However, in the relatively small-scale and structured flow fields that appeared in this study, abrupt and significant changes appeared in both time and space. Under these conditions, it would not be surprising to observe a significant variation in the behavior of the turbines in a wind farm.

There are no other high-frequency data from Goodnoe Hills without turbine interference that could be used to further analyze and document the findings described here. Even though turbine operation does add further turbulence and 
wake features to the flow, the pre-turbine composition of the flow is in most cases still recognizable, and components can at least partially be delineated. This is especially so when working with small machines; for example. $100 \mathrm{~kW}$ or less. Such data exist from an experiment carried out under agreenent with Fayette Industries, when some 50 sets of 20 -min-each, high-frequency wake data were acquired during the sumer of 1986 . The same kinematic wave signa* ture as found at the Goodnoe hills occurs repeatedly in the low-level flow some $80 \mathrm{~km}$ (50 miles) east of San Francisco in the Altanont Pass. These experiments were conducted when the wind speeds were relatively high, mainly during the morning and evening. Another well-known data set is from the vertical plane array in Clayton, New Mexico. The clayton data were collected in midwinter under very controlled conditions. The tower array in this experiment was erected in front of the MOO-OA turbine for prevailing wind directions. Again the 18-sensor array shows wave perturbations similar to those found in northern Calffornia and washington but with a considerably shorter wave length. 


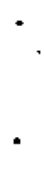




\subsection{REFERENCES}

Elilott, D. L., J. W. Buck, and J. C. Barnard. 1988. An Examination of Wake Effects and Power Production for a Group of Large Hind Turbines. PNL-6528, Pacific Northwest Laboratory, Richland, Washington.

Elliott, D. L., and J. C. Barnard. 1990. "Effects of Trees on Wind Flow Variability and Turbulence." J. Solar Energy Engineering Vol 112, 4:320-325. 
,

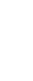




\section{DISTRIBUTION}

No, of

Copies

OFFSITE

12. DOE Office of Scientific and Technical Information

D. F. Ancona

U.S. Department of Energy Wind/Hydro/Ocean Diyision 1000 Independence Avenue, S.W. Forrestal Building, Room 55064 Washington, DC 20585

J. B. Cadogan

U.S. Department of Energy Wind/Hydrolocean Division 1000 Independence Avenue, $\$ . W$. Forrestal Building, Room 5 Fo64 Washington, $O C \quad 20585$

C. Castellano

U.S. Department of Energy Wind/Hydro/Ocean Division 1000 independence Avenue, S.W. Forrestal Building, Room 5F064 Washington, of 20585

5 C. 1. Aspliden

Route 1, Box 125

Roseland, VA 22967

B. Bajley

AWS Scientific, Inc.

55 Colvin Avenue

Albany, Ny 12206

R. W. Baker

277 WW Wintergreen PJace

Corvallis, OR 97330

N. Butler

Bonnevilla Power Administration

P.0. Box 3621

Portland, $O R \quad 97208$
No. of

Copies

K. Cousineau

Zond Systents Incorporated

13000 Jameson Road

Tehachapi, CA 93561

N. Kelley

Solar Energy Research Institute

1617 Cole Boulevard

Golden, $c 080401$

J. Kline

455 Larchwood Place

oakley, CA 94561

R. Lynette

R. Lynette and Associates, Inc.

15032 N.E. 40 th Street, Sulte 206 Redmond, WA 98052

E. McCarthy

U.5. Windpower

6952 Preston Avenue

Livernore, CA 94550

R. Nierenberg

153 Sacramento Avenue

San Anselmo, CA 94960

M. Sacarny

Second hind, Inc.

7 Davis Square

Somerville, MA 02144

L. Schienbein

Flowind corporation

1183 Quarry Lane

Pleasanton, CA 94566

D. Suehiro

HERS

P.0. Box 730

Honolulu, HI 96308 
No. of

Copies

R. Thresher

Solar Energy Research Institute

1617 Cole Boulevard

Golden, CO 80401

W. A. Vachon

W. A. Vachon \& Associates, Inc. P.0. Box 149

Manchester, MA 01944

S. Veenhuizen

United Industries Corp.

12835 Bel-Red Road

Bellevue, WA 98005

P. Veers

Sandia National Laboratories

Division 6225

Albuquerque, NM 87185

S. N. Walker

Department of Mechanical

Engineering

Oregon State University

Corvallis, OR 97331
No. of

Copies

ONS ITE

DOE Richland Operations office

E. C. Norman/R. B. Goranson

24 Pacific Northwest Laboratory

J. C. Barnard

D. L. Elliott

J. W. Falco

G. L. Gower

J. M. Hales

P. C. Hays

V. R. Morris

E. L. Owczarski

L. L. Wendell (10)

Publishing Coordination

Technical Report Files (5) 